\title{
Necessity and Feasibility of Building a New INDSANS at CARR
}

\author{
Li ZHANG ${ }^{1, a}$, Tian-Fu LI, b , Rong-Deng LIU ${ }^{1, c}$, Hong-Li WANG ${ }^{1, d}$, \\ Yun-Tao LIU ${ }^{1, e}$, Dong-Feng CHEN ${ }^{1, f}$ \\ ${ }^{1}$ China Institute of Atomic Energy, Beijing 102413, China \\ alzhang@ciae.ac.cn, ${ }^{\text {btianfu@ciae.ac.cn, } 9 \text { liurd104@163.com, }{ }^{d} h l w a n g @ c i a e . a c . c n, ~}$ \\ ytliu@ciae.ac.cn, 'dongfeng@ciae.ac.cn
}

${ }^{*}$ Corresponding author

Keywords: Neutron Scattering, Small Angle Scattering, Macromolecules, Nanomaterial.

\begin{abstract}
China advanced research reactor (CARR) is already critical in 2010 and constructed with three neutron guides. One small angle neutron scattering spectrometer (SANS) has almost finished. This paper introduces the characteristic, application and development situation of SANS at home and abroad. The necessity and favorable circumstance of building a new INDSANS at CARR as soon as possible is also analyzed.
\end{abstract}

\section{Advantage of SANS}

Small angle scattering (SAS) is a key tool in material study at the nanoscale, including small angle $\mathrm{x}$ ray scattering (SAXS), light scattering (LS) and small angle neutron scattering (SANS). SANS is a unique method because of the characterization of neutron [1-4]. The neutron source for SANS is from two kind of huge facility. The one is nuclear reactor, the other one is spallation source. These two source expense huge money, big volume. They are hard to maintain. So it's impossible to use SANS in every lab just like SAXS. It can be found only in the country which has these two sources.

The method to detect the structure of material by neutron developed fast after Chadwick found neutron in 1932. This method allows characterization, in a non-destructive way, of small particles (precipitates, cavities, etc.) ranging in size between 1 and $100 \mathrm{~nm}$. It can be used in many areas, like polymers, biology macromolecular and colloid. Besides this technique, giving statistical data representative of the whole sample, is particularly adapted to the study of structure materials like metals, magnetic clusters, ODS and so on [5-9]. Complementary to X-Ray techniques, SANS is a powerful non-destructive method for the investigation of materials and samples from various fields of activity, such as nuclear industry, energy industry and so on.

One example is showed friction stir welding (FSW) is a better method than electro-sparked deposition (ESD) welding for joining nanostructured ferritic alloy (NFA) MA957 by Transmission electron microscopy (TEM) and small angle neutron scattering (SANS)[10].Another one is studied MA957 produced with two microstructures characterized by different grain sizes (Tensile, creep and impact properties were found to be strongly dependent on the size of nano particle). The nano particles are around 1 to 30nm.The relation between structure and behavior can be get by the result of SANS and other techniques[11].

Other examples are showed about the study of reactor structure materials such as pressure vessel steel and so on[12-15].For example, the effect of hydrogen in irradiated reactor pressure vessel steels is studied by SANS. Because the cross section of hydrogen is totally different. So the relation between the content of hydrogen and the ability of creep can be get by SANS. The final experiment showed the structure of hydrogen can be studied even if the concentration of hydrogen is not more than 1-2ppm by SANS and the effect of hydrogen has relation with the type of steel. The nano structure in 8-20nm produced by hydrogen is good for improve embrittlement.

SANS is the method to detect the nanostructure in total $\mathrm{cm}$ size samples in above examples. So it's a unique method as others like TEM. Besides SANS is a better way when the nano structure in solution needs to be studied in industry [16-18]. 


\section{Situation in Foreign Countries}

In recent years, there have been major developments for SANS throughout the world because of the requirement for research. SANS is one of the fastest developing facilities in neutron center around the world.

The three SANS instruments with highest flux are operated at ILL, named D11, D22 and D33.There is three SANS instruments at NIST Center for Neutron Research (NCNR).Two is 30m SANS and the other one is $10 \mathrm{~m}$ SANS. Another VSANS is constructing. Further SANS instruments are used by scientists at FRM II, ANSTO, LLB, HMI, ORNL, the Budapest Neutron Center, ISIS, SINQ and elsewhere routinely. The list is as follows.

Tab. 1 SANS instruments around the world

\begin{tabular}{|c|c|c|c|c|}
\hline Instrument & $\begin{array}{l}\lambda \text { range } \\
(\mathrm{nm})\end{array}$ & $\begin{array}{l}\text { Q range } \\
(\mathrm{nm}-1)\end{array}$ & status & characterization \\
\hline NGB/NG7 (NIST) & $0.5 \sim 2.0$ & $0.015 \sim 6$ & operational & $64 \times 64 \mathrm{~cm}^{2}$ two dimensional He-3 PSD, resolution: $0.5 \times 0.5 \mathrm{~cm}^{2}$ \\
\hline 10m SANS (NIST) & $0.5 \sim 2.0$ & n.a. & operational & nSoft \\
\hline VSANS (NIST) & $0.5 \sim 2.0$ & $2 * 10-4 \sim 6$ & $\begin{array}{c}\text { Under } \\
\text { construction }\end{array}$ & $\begin{array}{l}\text { Multi pinhole, } 40 \mathrm{~m} \text { geometry. Position-sensitive detector, resolution: } \\
\qquad 0.1 \times 0.1 \mathrm{~cm}^{2}\end{array}$ \\
\hline PACE (LLB) & $0.4 \sim 2$ & $0.02 \sim 5$ & operational & Concentric rings detector $\mathrm{dR}=1 \mathrm{~cm}$ TOF option $\mathrm{BF} 3$ detector \\
\hline PAXY & $0.4 \sim 2$ & $0.03 \sim 10$ & operational & resolution: $5 \times 5 \mathrm{~mm}^{2}$ two dimensional $\mathrm{He}-3 \mathrm{PSD}$ \\
\hline PAXE (LLB) & $0.4 \sim 2$ & $0.05 \sim 5$ & operational & resolution: $10 \mathrm{~mm} \times 10 \mathrm{~mm}$ two dimensional $\mathrm{He}-3 \mathrm{PSD}$, TOF option \\
\hline TPA (LLB) & $0.7 \sim 1.6$ & $0.002 \sim 0.2$ & $\begin{array}{c}\text { commissionin } \\
\mathrm{g}\end{array}$ & Image plate detector, multibeam collimation \\
\hline SANS-I (PSI) & $0.45 \sim 2$ & $0.006 \sim 5.4$ & operational & $\begin{array}{l}\text { Polarization }(0.47-1 \mathrm{~nm}) \text {,in situ DLS, rheology sample environment, neutron } \\
\text { lenses, } 11 \mathrm{~T} \text { SANS cryomagnet } \\
\text { resolution: } 7.5 \times 7.5 \mathrm{~mm}^{2} \text { two dimensional He-3 PSD, } 0.5 \mathrm{~m} \text { offset }\end{array}$ \\
\hline SANS-II (PSI) & $0.45 \sim 2$ & $0.02 \sim 3.5$ & operational & $\begin{array}{l}\text { Controller sample temperature and humidity conditions, } 11 \mathrm{~T} \text { SANS cryomagnet } \\
\text { resolution: } 5 \times 5 \mathrm{~mm}^{2} \text { two dimensional He-3 PSD, } 0.5 \mathrm{~m} \text { offset }\end{array}$ \\
\hline V16 (HMI) & $0.35 \sim 3$ & $0.001 \sim 8.5$ & operational & Optional high resolution mode using multi pinhole grid collimation, TOF mode \\
\hline D11 (ILL) & $0.45 \sim 4$ & $0.01 \sim 20$ & operational & resolution:7.5mm $\times 7.5 \mathrm{~mm}$ two dimensional $\mathrm{He}-3 \mathrm{PSD}$ \\
\hline D22 (ILL) & $0.45 \sim 4$ & $0.0015 \sim 10$ & operational & 128 one dimensional $\mathrm{He}-3 \mathrm{PSD}$ arrays \\
\hline D33 (ILL) & $0.45 \sim 4$ & $0.003 \sim 10$ & operational & resolution: $7.5 \mathrm{~mm} \times 7.5 \mathrm{~mm}$ two dimensional He-3 PSD \\
\hline $\begin{array}{c}\text { KWS1 } \\
\text { (FRM II -JCNJS) }\end{array}$ & $0.45 \sim 2$ & $0.001 \sim 3$ & operational & $\begin{array}{l}\text { Polarization, GISANS option for magnetic and non-magnetic problems, chopper } \\
\text { option }\end{array}$ \\
\hline $\begin{array}{c}\text { KWS2 } \\
\text { (FRM II -JCNJS) }\end{array}$ & $0.45 \sim 2$ & $0.001 \sim 3$ & operational & High intensity, chopper option \\
\hline $\begin{array}{c}\text { KWS3 } \\
\text { (FRM II -JCNJS) }\end{array}$ & $0.8 \sim 2$ & $0.0005 \sim 0.04$ & operational & Reflectometry mode \\
\hline QUOKKA (ANSTO) & $0.45 \sim 2$ & $\begin{array}{c}0.0008 \sim 1 \\
0.015-1\end{array}$ & operational & Polarization, large $\operatorname{PSD}\left(1 \mathrm{~m}^{2}\right)$, multiple sample environment, \\
\hline $\begin{array}{l}\text { SANS-1 } \\
\text { (FRM II and GKSS) }\end{array}$ & $0.45 \sim 2$ & $0.001 \sim 20$ & operational & $\begin{array}{c}\text { Polarization, two selectors, chopper option, displaceable detector arrays }\left(1 \mathrm{~m}^{2}\right) \text {, } \\
\text { second detector option and large } \operatorname{PSD}\left(1 \mathrm{~m}^{2}\right)\end{array}$ \\
\hline Bio-SANS (ORNL) & $0.6 \sim 3$ & $0.002 \sim 1$ & operational & All kind of sample environment \\
\hline SANS2d (ISIS-TS2) & n.a. & $0.001 \sim 25$ & operational & Two detectors, TOF \\
\hline HI-SANS (J-PARC) & n.a. & $0.01 \sim 150$ & operational & TOF, large PSD and focusing devices \\
\hline
\end{tabular}

\section{Situations in China}

Few sources can be used for neutron scattering in China by now. There's only reactor in the beginning. Neutron scattering was not the purpose for that reactor in the design before the construction. So it's hard to do SANS on it. 
Neutron scattering developed early in China based on the importance of neutron scattering for material research. The 15 MW Heavy Water Research Reactor (HWRR) at CIAE in Beijing was the unique neutron source available for neutron scattering experiments in 1960s. Six neutron scattering instrument so are installed at the four beam tubes on HWRR. Since 1980's, intense cooperation on neutron scattering researches have been set up between CIAE and more than 30 famous domestic and international Institute, university and laboratory. Tremendous of research works on condensed matter and bio-material have been carried out based on local research team and closed collaboration with user community. It's good for the development of neutron scattering and the training of scientist.

China Advanced Research Reactor (CARR) built at China Institute of Atomic Energy(CIAE) has got full power of $60 \mathrm{MW}$, which has high neutron flux of $8 \times 10^{14} / \mathrm{sec} \cdot \mathrm{cm}^{2}$ in $2000 \mathrm{~s}$. To do better research by neutron scattering one of the object of CARR is establishment of a complete set of spectrometers used as the tool for research in the fields of life sciences, material sciences, physics, chemistry and chemical engineering, minerals, environment sciences, industrial and engineering applications. The aim is building the laboratory into a national neutron scattering key laboratory at international advance level, serving as a national neutron scattering research and training center as well as an international research center in the Asia region. So the construction of CARR is very suitable for neutron scattering. The background is low and the cold source is building by now. The cold neutron for SANS, REF and so on will be given in the guide hall by cold source.

Upon the financial support from the Chinese government, the SANS spectrometer with basic performance has already built in the guide hall.

Tab. 2 the parameter of SANS

\begin{tabular}{ll}
\hline Part name & Characteristics \\
\hline Source & Neutron guide: CARR-CNGD \\
& cross section: $50 \mathrm{~mm} \times 50 \mathrm{~mm}$ \\
Monochromator & Mechanical velocity selector with variable speed and pitch): \\
Wavelength Range & $4.0 \sim 20.0 \AA$ \\
Wavelength Resolution & $\Delta \lambda / \lambda(\mathrm{FWHM})=10 \% \sim 22 \%$ \\
Source-to-Sample Distance & 4 to $16 \mathrm{~m}$ in $4 \mathrm{~m}, 10 \mathrm{~m}, 16 \mathrm{~m}$ via insertion of guide sections \\
Sample-to-Detector Distance & $1.0 \sim 15 \mathrm{~m}$ adjust continuously \\
Collimation & Circular pinhole collimation or focusing lenses \\
Sample Size & $\Phi 5 \mathrm{~mm} \sim \Phi 25 \mathrm{~mm}$ \\
Q-range & $0.0008 \sim 0.6 \AA^{-1}$ \\
Size Regime & $10 \sim 5000 \AA$ \\
Detector & $640 \mathrm{~mm} \times 640 \mathrm{~mm}{ }^{3} \mathrm{He}$ position-sensitive proportional counter, \\
\end{tabular}

Moreover, the basic sample stage has been established based on the application in Polymer area.

Neutrons are the ideal probes to study the structure and the behavior of the sample due to the fact that neutrons enabling deeper penetration and much sensitivity to light elements as hydrogen, lithium, boron and so on. Compare with the other methods like SAXS and TEM SANS can do with big sample in statistics experiment. It's much easier to prepare a sample for SANS. And it can do with magnet sample to get much more exact information than others. For the deeper penetration it can work with complex sample environment like magnet, pressure cell or other in-site test ${ }^{[9,27-31]}$. This is so 
important for industry and other area. Because of the busy request for SANS many neutron scattering centers have more than one SANS. The best way is to build another industry SANS to do such kind of work on CARR. So much more work is waiting for another new IndSANS.

There's another reactor near Chengdu and with some neutron scattering instruments around it. It's very easy for the scientist in southwest area. The only one spallation source is in constructing in Guangdong Province in south of China. Neutron scattering is its main purpose. So these three sources should be very good for the whole scientist society in China.

\section{Opportunity to Build a New INDSANS at CARR}

Although the present facilities have basic functions, it has not taken full advantage of the high flux of CARR. More sophisticated techniques like horizontal field magnet, bearing sample stage and so on should also been developed. Equipment with the devices like magnet, pressure and so on is very important for the research on structure materials like ODS and pressure vessel of reactor. Other examples like kinetics and morphology of precipitate growth in alloys and glasses; Defect structures (e.g. micro cracks, voids) resulting from creep, fatigue or radiation damage; Grain and defect structures in nanocrystalline metals and ceramics and so on ${ }^{[32-41]}$ are also need this method. It's a good opportunity to build an Ind-SANS to satisfy the demanding of material scientist from many areas.

Scientists have enough experience to build another SANS after finishing the first one. The technique can be developed much more by build another Ind-SANS. The gap will be smaller between China and developed country.

\section{References}

[1] G. L. Squires. Introduction to Thermal Neutron Scattering, Second, Cambridge University Press, 1978, pp. 5-30.

[2] SH. Chen. Small angle neutron scattering studies of the structure and interaction in micellar and micro emulsion systems. Ann. Rev. Phys. Chem. 37(1986) 351-399.

[3] J. S. Higgins, H. C. Benoit. Polymers and Neutron Scattering. Clarendon Press-Oxford, 1994.

[4] DZ Ding, CT Ye, ZX Zhao, etc.. Neutron Physics, Second ed., China Nuclear Energy Press, 2005.

[5] P. Miao, G.R. Odette, T. Yamamoto, etc. Thermal stability of nano-structured ferritic alloy. Journal of Nuclear Materials 377 (2008) 59-64.

[6] M. Ohnuma, J. Suzuki, S. Ohtsuka, etc. A new method for the quantitative analysis of the scale and composition of nanosized oxide in 9Cr-ODS steel. Acta Materialia 57 (2009) 5571-5581.

[7] M.H. Mathon, Y. de Carlan, G. Geoffroy, etc. A SANS investigation of the irradiation-enhanced $\alpha-\alpha^{\prime}$ phases separation in $7-12$ Cr martensitic steels. J. Nucl. Mater. 312 (2003) 236-248.

[8] C. Cayron, A. Montani, D. Venet, etc. Identification of new phases in annealed Fe-18CrWTi ODS powders. J. Nucl. Mater. 399 (2010) 219-224.

[9] M.J. Alinger, PhD dissertation, University of California Santa Barbara, 2004

[10]P. Miao, G.R. Odette, J. Gould, etc. The microstructure and strength properties of MA957 nanostructured ferritic alloy joints produced by friction stir and electro-spark deposition welding. J. Nucl. Mater. 367-370 (2007) 1197-1202.

[11] S. Yamashita, N. Akasaka, S. Ohnuki. Nano-oxide particle stability of 9-12Cr grain morphology modified ODS steels under neutron irradiation. J. Nucl. Mater. 329-333 (2004) 377-381. 
[12] A. Ulbricht, J. Böhmert, M, Uhlemann etc., Small-angle neutron scattering study on the effect of hydrogen in irradiated reactor pressure vessel steels. J. Nucl. Mater. 336 (2005) 90 - 96.

[13] S.C. Glade, B.D. Wirth, G.R. Odette, etc., Positron annihilation spectroscopy and small angle neutron scattering characterization of nanostructural features in high-nickel model reactor pressure vessel steels. J. Nucl. Mater. 351 (2006) 197 - 208.

[14] M.K. Miller, B.D. Wirth, G.R. Odette, etc., Precipitation in neutron-irradiated Fe_/Cu and $\mathrm{Fe} / \mathrm{Cu} / \mathrm{Mn}$ model alloys: a comparison of APT and SANS data. Materials Science and Engineering A353 (2003) 133-139.

[15] S.C. Glade, B.D. Wirth, G.R. Odette, etc., Positron annihilation spectroscopy and small-angle neutron scattering characterization of the effect of $\mathrm{Mn}$ on the nanostructural features formed in irradiated Fe-Cu-Mn alloys. Philosophical Magazine, 85 (2005) 629 - 639.

[16] A. Plaue, A. Gelis, K. Czerwinski, etc., Small-Angle Neutron Scattering Study of Plutonium Third Phase Formation in 30\% TBP/HNO3/Alkane Diluent Systems. Solvent Extraction and Ion Exchange, 24 (2006) 283-298.

[17] S. Nave, C. Mandin, L. Martinet, etc., Supramolecular organisation of tri-n-butyl phosphate in organic diluent on approaching third phase transition. Phys. Chem. Chem. Phys., 6 (2004) 799 - 808.

[18] R. Chiarizia, K.L. Nash, M.P. Jensen, etc., Application of the Baxter Model for Hard Spheres with Surface Adhesion to SANS Data for the U (VI)-HNO3, TBP-n-Dodecane System. Langmuir 19 (2003) 9592-9599.

[19] Information on http://www.ill.eu/about/future-planning/perspectives-opportunities

[20] A. Wiedenmann, U. Keiderling, K. Habicht, etc., Dynamics of Field-Induced Ordering in Magnetic Colloids Studied by New Time-Resolved Small-Angle Neutron-Scattering Techniques. Physical Review Letters 97 (2006) 057202-057208.

[21]R. Gilles, A. Ostermann, W. Petry. Monte Carlo simulations of the new small-angle neutron scattering instrument SANS-1 at the Heinz Maier-Leibnitz Forschungsneutronenquelle. Journal of Applied Crystallography 40 (2007) S428-432.

[22] CT Ye, YT Liu. Neutron scattering technology and its application. Physics, 35 (2006) 961-968.

[23]CT Ye. Situation and prospect of thermal neutron scattering in China. Nuclear Technology, 16 (1993) 505-510.

[24]DF Chen, C Gou, CT Ye. The neutron scattering project on China Advanced Research Reactor (CARR). Nuclear Technology, 28 (2005) 127-129.

[25] TH Yang, YP Xu, X Zhao, etc..The rearrangement and test of two dimensional detector for SANS. Annual Report of China Institute of atomic energy, 1994 84-85.

[26] LF He, HL Wang, L Zhang. Simulation for SANS in CARR. Annual Report of China Institute of atomic energy, 2007186.

[27] M.J. Alinger, G.R. Odette, D.T. Hoelzer, On the role of alloy composition and processing parameters in nanocluster formation and dispersion strengthening in nanostructured ferritic alloys. Acta Mater 57 (2009) 392-406

[28] K. L. Krycka, R. A. Booth, C. R. Hogg, etc., Core-Shell Magnetic Morphology of Structurally Uniform Magnetite Nanoparticles. PRL 104 (2010) 147204.

[29] B. G. Ueland, J.W. Lynn, M. Laver, etc., Origin of Electric-Field-Induced Magnetization in Multiferroic HoMnO3, PRL 104 (2010) 147204. 
[30]A. Wiedenmann. Small-angle neutron scattering investigations of magnetic nanostructures and interfaces using polarized neutrons. Physica B 297 (2001) 226-233.

[31] A Wiedenmann, M. Kammel, A. Heinemann, etc., Nanostructures and ordering phenomena in ferrofluids investigated using polarized small angle neutron scattering. J. Phys.: Condens. Matter 18 (2006) S2713-S2736.

[32] MH Huang, S Mao, H. Feick, etc., Room-temperature ultraviolet nanowire nanolasers. Science, 292 (2001) 1897-1899.

[33]ZW Pan, ZR Dai, ZL Wang. Nanobelts of semiconducting oxides. Science, 291(2001) 1947-1949.

[34] YN Xia, PD Yang, YG Sun, etc., One-dimensional nanostructures: Synthesis, characterization, and applications. Advanced materials, 15(2003) 353-389.

[35] A.M. Morales, C.M. Lieber, A laser ablation method for the synthesis of crystalline semiconductor nanowires. Science, 279 (1998) 208-211.

[36] M. Alexandre, P. Dubois, Polymer-layered silicate nanocomposites: preparation, properties and uses of a new class of materials. Materials science \& engineering r-reports, 28(2000) 1-63.

[37] S.S. Fan, M.G. Chapline, N.R. Franklin, etc., Self-oriented regular arrays of carbon nanotubes and their field emission properties. Science, 283 (1999) 512-514.

[38]R.Z. Valiev, R.K. Islamgaliev, I.V. Alexandrov Bulk nanostructured materials from severe plastic deformation. Progress in materials science, 45 (2000) 103-189.

[39]ZF Ren, ZP Huang, JW Xu, etc., Synthesis of large arrays of well-aligned carbon nanotubes on glass. Science, 282(1998) 1105-1107.

[40] MH Huang, YY Wu, H. Feick, etc., Catalytic growth of zinc oxide nanowires by vapor transport. Advanced materials, 13(2001) 113-116.

[41]C.B. Murray, C.R. Kagan, M.G. Bawendi, Synthesis and characterization of monodisperse nanocrystals and close-packed nanocrystal assemblies. Annual review of materials science, 30 (2000) 545-610. 